\title{
Primary Cleft Repair in Adult Patients with Untreated Cleft Lip and Palate Deformity
}

\author{
KARAM A. ALLAM, M.D.; MOSTAFA M. HAREDY, M.D. and AHMED G. ABDELMEGEED, M.D. \\ The Department of Plastic Surgery, Faculty of Medicine, Sohag University, Sohag, Egypt
}

\begin{abstract}
Background: Referring cleft patients to a specialized medical center at the earliest possible time after birth provides the best outcome and minimizes possible complications. For diversity of economic and social factors, some patients may not receive the adequate care and surgical repair at the proper time and present late in adulthood with totally or partially unrepaired clefts.
\end{abstract}

Patients and Methods: Patients with untreated primary cleft deformity older than 16 years, who were treated at The Department of Plastic Surgery, Sohag University, in the period between 2009 and 2019, were retrospectively reviewed. The assessment included evaluation of demographic data (age at first consultation and sex distribution), type and laterality of cleft, patients' social and educational status, and previous cleft surgeries. Patients' satisfaction following surgery was also assessed.

Results: All adult patients with untreated primary cleft deformity in this study were males, unilateral cleft lip and palate was the commonest deformity. Majority of patients had no education. Marriage was the main motive for having surgery done. All patients were moderately to highly satisfied with surgical outcomes.

Conclusions: Although uncommon nowadays, unrepaired primary cleft deformity in adults can still be seldom reported in some patients especially in lower socioeconomic classes. Surgical repair is more challenging and need more radical solutions, but it achieves good satisfaction in all patients.

Key Words: Cleft lip and palate - Adults, Late presentation - Unrepaired-Untreated cleft.

\section{INTRODUCTION}

Cleft lip and/or palate is one of the most common congenital deformities that have cosmetic, psychosocial and functional impacts especially on speech, hearing, feeding and dental development [1]. Average incidence of cleft deformity is 1 in 600 to 1 in 1,000 live-births [2,3]. One of the most critical aspects for achieving best results is to select the best time for repair; too early surgical intervention may affect facial growth while late intervention may compromise speech [4]. Referring cleft patients to a specialized medical center with a multidisciplinary team service at the earliest possible time after birth would provide the best outcome and minimize possible complications [5]. Variable social and financial factor may affect timing of patient's access to medical service and cleft care, some patients may not receive the adequate care and surgical repair at the proper time and present late in adulthood with totally or partially unrepaired clefts. Late presentation of adult patients with untreated clefts has been published in different reports that discussed facial growth or dental abnormalities, surgical procedures and compared outcomes to early cleft repair [6-12].

This study aimed at discussing the epidemiological, morphological, and social characteristics of an adult patient population with unrepaired cleft lip and/or palate, their motivation for having cleft repaired, and surveying their satisfaction following surgeries.

\section{PATIENTS AND METHODS}

This retrospective study was conducted to identify all adult patients with untreated cleft lip and/or palate who were presented and treated at The Department of Plastic and Reconstructive Surgery in Sohag University between July 2009 and November 2019 . The study was approved by the Research Ethical Committee of the author's institution. All the charts for cleft patients were reviewed. Patients 16 years old or morepresented with untreated primary cleft lip and/or cleft palate deformity who had complete records were included in this study. All cleft patients were seen and followed by a multidisciplinary cleft team consisted of a plastic surgeon, dentist, orthodontist, speech therapist, and audiologist. The assessment included evaluation of demographic data (age at first consultation and sex distribution), type and laterality of cleft, patients' social and educational status, and previous cleft surgeries. We used a simple fivepoint Likert scale to assess patients' satisfaction following surgery with 1 (highly dissatisfied) and 5 (highly satisfied) [13]. 


\section{Surgical technique:}

Cleft palate surgeries were done under general anesthesia while cleft lip repair was done under general or local anesthesia according to severity of the deformity and patient's preference. Cleft lip deformities were treated by Mohler [14], while bilateral clefts were treated with one stage Mulliken repair [15]. Vomerine osteotomy and setback of severe prominent premaxilla helped tension free lip repair. Palatoplasty was performed using von Langenbeck (straight line closure of the palate with lateral palatal releases), and Sommerlad [16] (radical muscle dissection) techniques. Whenever feasible, simultaneous cleft lip and palate repair was done in one stage. If not feasible, we prefer to do palatal repair first to get the patient back to do lip repair. Nasal deformity was managed according to severity. Severe nasal deformity was aggressively handled to dissect and reposition alar cartilage, elongate short columella and fix the deviated septum. Speech assessment is part of routine protocol and speech therapy is decided according to each patient's need. Patients with dental deformities were advised to follow with our orthodontist.

\section{RESULTS}

Patients' records of 1767 cleft patients who were treated at The Department of Plastic Surgery, Sohag University were reviewed; 17 patients with minimum age 16 years and unrepaired clefts (all of them are males) who had complete medical records were identified and included in the study. The age at the initial assessment ranged from 16 to 33 years (mean, 19.2 years). Bilateral cleft lip and palate (BCLP) was demonstrated in 2 patients, unilateral cleft lip and palate (UCLP) in 11 patients, whereas isolated cleft lip affected 3 patients, and isolated palatal cleft was found in 1 patient. Table (1) summarizes the cleft side. Local anesthesia was used in 4 patients undergoing unilateral cleft lip repair. Of the 17 patients, 3 had previous lip repair surgeries ( 2 unilateral and 1 bilateral) with the palate left unrepaired. The type of education included vocational school in 3 patients, primary school in 5 patients while 9 patients had no education. The motive for doing surgery at that age was marriage in 11 patients, getting a job in 4 patients and avoiding bullying in 2 patients. Reviewing patients' satisfaction on 5-point Likert scale showed satisfaction score ranged from 4 to 5 (mean 4.4). Three patients started postoperative speech therapy with subjective reasonable improvement documented by patients, one of them also started orthodontic management while most patients (14) did not follow with other team members especially orthodontist and speech pathologist and expressed no need for further work after surgery.

Table (1): Cleft type and laterality.

\begin{tabular}{lccc}
\hline & Unilateral & Bilateral & Total \\
\hline CLP & 11 & 2 & 13 \\
CL & 3 & - & 3 \\
CP & - & 1 & 1 \\
\hline CL: Cleft lip only. & CLP: Cleft lip and palate. & CP: Cleft palate only.
\end{tabular}

\section{Case Presentation:}

\section{Case 1:}

Twenty-seven years old man with left incomplete CL (Fig. 1), from a rural residence who had no treatment during childhood, as family could not afford treatment, and as he grew as a farmer in a rural area without going to school, he paid a little attention to the deformity. He sought medical advice regarding deformity at this age after being rejected from marriage due to this deformity. He had his lip repaired completed utilizing Mohler repair. The patient was very satisfied about the result of the surgery.

Fig. (1): Twenty-seven years old man with left incomplete cleft lip; pre-operative (A) and two month post-operative (B) frontal views.
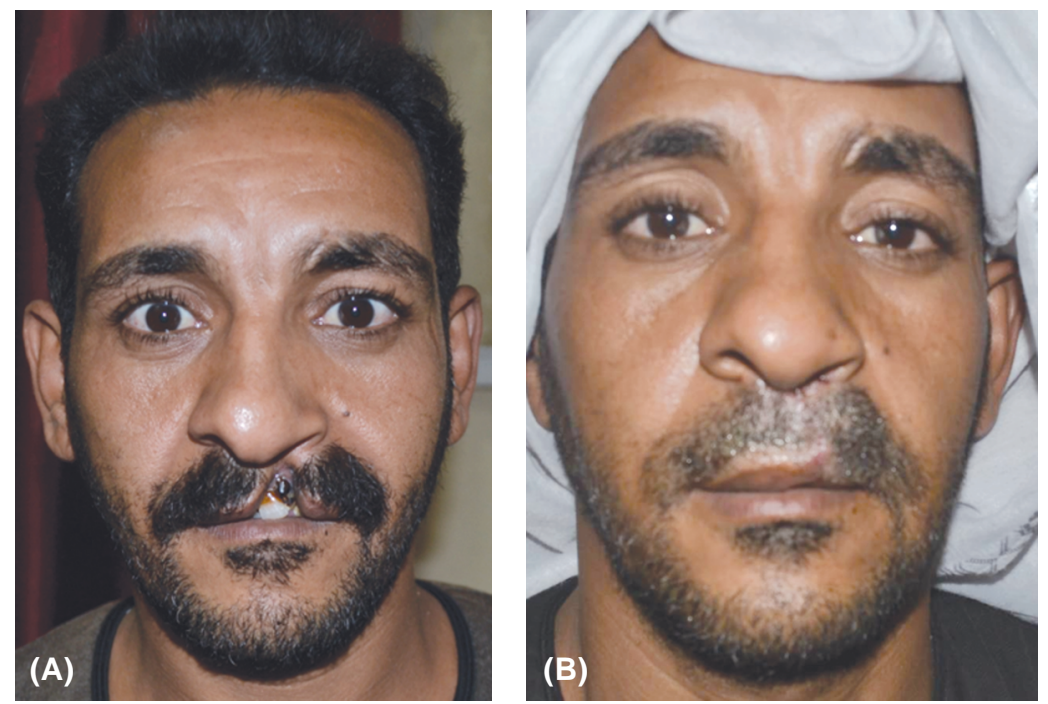


\section{Case 2:}

Eighteen years old male presented with an unrepaired bilateral complete cleft lip and palate (Fig. 2). He came from a poor countryside where he received not early treatment because of complex financial and social issues. He had no education and no permanent job, he sought for different jobs

(A)



(C)

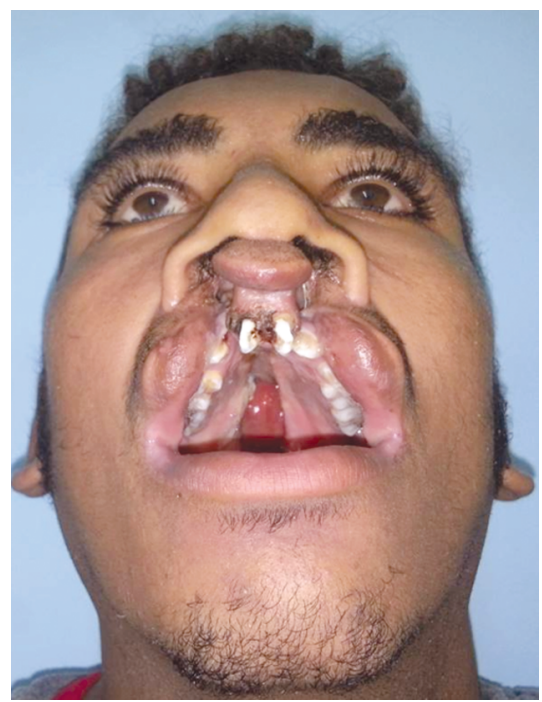

and was rejected primarily for his facial appearance, and his primary motivation for surgery was to have a job. He had poor speech, but this was not his primary concern. He underwent palatal repair of the cleft palate, using von Langenbeck technique. We planned his palatal repair first to make sure he will come back but he did not return for lip repair at our department.

(B)

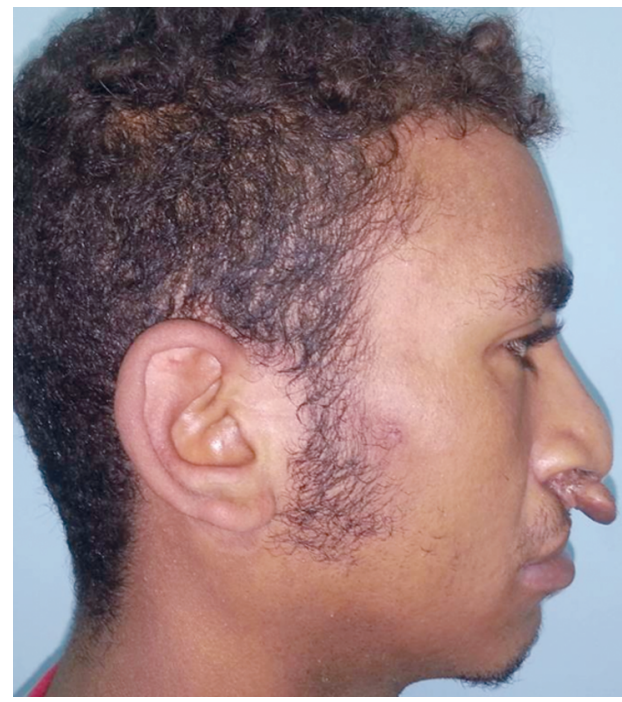

(D)

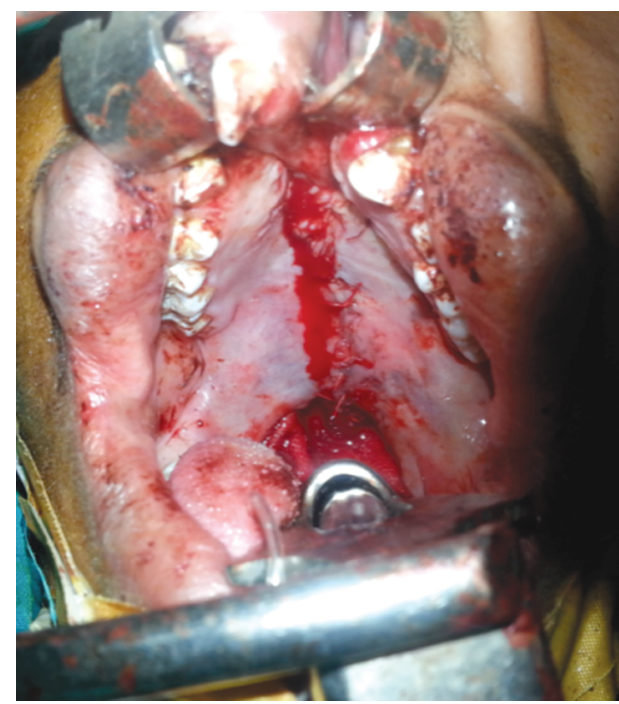

Fig. (2): Eighteen years old male with bilateral complete cleft lip and palate; pre-operative frontal (A), lateral (B) and intraoral $(C)$ views, and intraoperative view following palatal repair (D).

\section{Case 3:}

Twenty years old man who was born with left complete cleft lip and palate (Fig. 3). He came from a rural residence and he had only primary school education. He had lip repair during childhood, but family could not afford further treatment. His main concern was poor speech and limited communication with people, and his motivation for surgery was the planning for marriage. With the availability of cleft team in Upper Egypt and increased public awareness, he came to us looking for palatal repair and speech improvement. He had his palatal cleft repaired using Summerland radical muscle dissection technique. The palatal repair outcome 7 days postoperatively is shown in Fig. (3). 



Fig. (3): Twenty years old man with left complete cleft lip and palate who had lip repair during childhood, but had no palatal cleft repair; frontal (A) and intraoral (B) views before palatal repair, and one week postoperative intraoral view (C).

\section{DISCUSSION}

The objectives of treatment of cleft lip and palate patients include improving cosmetic appearance, removing cleft stigma to improve quality of life and social interaction, obtaining normal speech and facial growth, and normal dentition [17]. Optimal timing of cleft lip and palate surgery is still controversial, $[\mathbf{1 8 , 1 9 ]}$ and argument continue mainly regarding the effect of early repair on facial growth and effect of late repair on speech. Literature reported primary cleft lip repair done from age of 2 days to as late as 1 year, but the commonest protocols perform lip repair between 3 and 6 months of age [18-20]. Most cleft palate protocols perform repair before the age of 24 months, with traditional timeline being around 9 to 12 months of age in most cleft centers [21,22].

Treatment delay has been reported in literature and explained by a variety of socioeconomic reasons [10-12]. In a Nigerian study of 43 untreated cleft patients, with age range of 6-37 years, the most common reasons for delayed presentation were lack of money $(56.7 \%)$, followed by lack of health care services nearby (18.4\%) and lack of awareness of treatment availability (13.3\%) [23]. Withincreased public awareness, rising legislations that provided health insurance for all children, and governmental hospitals that provide free surgeries for those kids in Egypt including centers with multi-specialty cleft treating teams, it is not common now to find an adult patient with untreated cleft deformity. Out of 1767 cleft patients who were treated at our department, only 17 patients $(0.001 \%)$ were presented late after age of 16 years for primary cleft surgery.
It is interesting that all our patients were males, which may reflect the fact that our community gives more attention to cosmetic appearance associated with cleft lip and speech problems associated with cleft palate in female individuals more than male individuals, mainly for fear of being unmarried.

It is well known that early assessment and management of cleft patients improve the cosmetic appearance, speech performance and the overall psychological aspects of these patients, $[\mathbf{1 7 , 2 4}]$ while patients with delayed treatment of their cleft are more prone to poorer outcome of speech, impaired social relationships and potential long term psychological impacts [24]. On the other hand, evaluating of the oral and profile examination of our patients revealed that no obvious regression in the antero-posterior and transverse maxillary dimensions, which can be explained by absence of the impact of previous palatal surgical intervention on the maxillary growth. The impaired maxillary development frequently encountered following surgery has been attributed to multiple factors including scar tissue contraction, disruption of blood supply, affection of the growth centers, [25] in addition to the possible decreased growth potential associated with the cleft itself [26].

Surgical repair of the cleft in the adult patient poses some challenges which include a relatively wider cleft gap, [27] necessitating more aggressive soft tissue dissection. This is more obvious in the bilateral complete cleft deformity, where the more protruded and/or twisted premaxilla makes the surgery more difficult and can create tension on 
the repair. It is well agreed now that reconstructed oral muscular sling in lip repair during early childhood plays an important role in preventing the protrusion of the premaxilla, frequently seen in the unrepaired cleft in adult patients [25]. Additionally, cleft surgery in adults produces more blood loss, especially during cleft palate repair, than in infants [23]. More postoperative edema, resulting from the more aggressive soft tissue dissection, has been also reported in cleft surgery for adult patients [27]. On the other hand, operating on the adult patient with more bulky tissue with more distinguishable anatomic landmarks makes it is relatively easier to identify and dissect than in infant patients. Additionally, definite rhinoplasty for the cleft nasal deformity can be combined in the same session of lip repair, as complete growth of nasal cartilages has been attained. Moreover, it is possible to use local anesthesia for lip repair in adult patient obviating the need for general anesthesia in these patients [28].

Speech problems associated with untreated cleft lip and/or palate in the elderly population have associated life-long impacts on the quality of life for these patients. Surgical repair can improve speech in these elderly patients [29]. Facial appearance was the main concern in most of our patients in this study including those with palatal cleft, while speech defects were not significantly affecting their life or communication with others in their communities considering their socioeconomic, educational and residency backgrounds. Out team recommended speech therapy and follow-up for all patients after cleft palate repair, three patients started post-operative speech therapy and showed reasonable improvement, two of them did not complete all needed sessions.

Post-operative satisfaction in our patient population ranged from moderate to high satisfaction with their results with regard aesthetic outcomes and social interaction, which confirms the overall improvement in the quality of life appreciated in previous reports $[\mathbf{3 0 , 3 1 ]}$.

\section{Conclusion:}

Although uncommon nowadays, unrepaired primary cleft deformity in adults can still be seldom reported in some patients especially in lower socioeconomic classes and lower educational levels. While it is well known that the postoperative improvement is far better during infancy, especially in speech outcome, cleft surgery for adult patients with unrepaired cleft, although more challenging and needs more radical solutions, can give satisfactory results.

\section{REFERENCES}

1- Strauss R.P. and Cassell C.H.: Critical issues in craniofacial care: Quality of life, costs of care, and implications of prenatal diagnosis. Acad. Pediatr., 9: 427-432, 2009.

2- Basseri B., Kianmahd B.D., Roostaeian J., et al.: Current national incidence, trends, and health care resource utilization of cleft lip-cleft palate. Plast. Reconstr. Surg., 127: 1255-1262, 2011.

3- Watkins S.E., Meyer R.E., Strauss R.P., et al.: Classification, epidemiology, and genetics of orofacial clefts. Clin. Plast. Surg., 41: 149-163, 2014.

4- Abbott M.M., Kokorowski P.J. and Meara J.G.: Timeliness of surgical care in children with special health care needs: Delayed palate repair for publicly insured and minority children with cleft palate. J. Pediatr. Surg., 46: 1319$1324,2011$.

5- Zaluzec R.M., Rodby K.A., Bradford P.S., et al.: Delay in Cleft Lip and Palate Surgical Repair: An Institutional Review on Cleft Health Disparities in an Urban Population. J. Craniofac. Surg. Nov-Dec., 30 (8): 2328-2331, 2019.

6- Capelozza Júnior L., Taniguchi S.M. and da Silva Júnior O.G.: Craniofacial morphology of adult unoperated complete unilateral cleft lip and palate patients. Cleft Palate Craniofac. J. Jul;., 30 (4): 376-381, 1993.

7- Derijcke A., Kuijpers-Jagtman A.M., Lekkas C., et al.: Dental arch dimensions in unoperated adult cleft-palate patients: An analysis of 37 cases. J. Craniofac. Genet Dev. Biol. Jan-Mar., 14 (1): 69-74, 1994.

8- Will L.A.: Growth and development in patients with untreated clefts. Cleft Palate Craniofac. J. Nov., 37 (6): 523-526, 2000.

9- Shetye P.R.: Facial growth of adults with unoperated clefts. Clin. Plast. Surg. Apr., 31 (2): 361-71, 2004.

10- Mantinàos C.: Untreated cleft lip in an aged patient. Plast. Reconstr. Surg. May, 87 (5): 954-955, 1991.

11- Ward C.M. and James I.: Surgery of 346 patients with unoperated cleft lip and palate in Sri Lanka. Cleft Palate J. Jan., 27 (1): 11-15; discussion 15-17, 1990.

12- Morioka D., Yoshimoto S., Udagawa A., et al.: Primary repair in adult patients with untreated cleft lip-cleft palate. Plast. Reconstr. Surg. Dec., 120 (7): 1981-1988, 2007.

13- Likert R.: A technique for the measurements of attitudes. Archives of Psychology, 140 (22): 5-55, 1932.

14- Mohler L.R.: Unilateral cleft lip repair. Plast. Reconstr. Surg., 80: 511-517, 1987.

15- Mulliken J.B.: Principles and techniques of bilateral complete cleft lip repair. Plast. Reconstr. Surg. Apr., 75 (4): 477-487, 1985.

16- Sommerlad B.C.: A technique for cleft palate repair. Plast. Reconstr. Surg. Nov., 112 (6): 1542-1548, 2003.

17- Rohrich R.J., Love E.J., Byrd H.S. and Johns D.F.: Optimal timing of cleft palate closure. Plast. Reconstr. Surg. Aug., 106 (2): 413-21; quiz 422; discussion 423-425, 2000.

18- Kobus K. and Kobus-Zalesna K.: Timing of cleft lip and palate repair. Dev. Period Med., 18: 79-83, 2014. 
19- Chow I., Purnell C.A., Hanwright P.J., et al.: Evaluating the rule of 10s in cleft lip repair: Do data support dogma? Plast. Reconstr. Surg., 138: 670-679, 2016.

20- Hammoudeh J.A., Imahiyerobo T.A., Liang F., et al.: Early Cleft Lip Repair Revisited: A Safe and Effective Approach Utilizing a Multidisciplinary Protocol. Plast. Reconstr. Surg. Glob Open. Jun., 26; 5 (6): e1340, 2017.

21- Dorf D.S. and Curtin J.W.: Early cleft palate repair and speech outcome. Plast. Reconstr. Surg., 70: 74-81, 1982.

22- Bluher A.E., Cunningham T.D. and Reeves T.D.: Effect of Cleft Palate Repair Timing on Inpatient Complication Rate: Review of a National Database. J. Craniofac. Surg. Nov., 6, 2020.

23- Adeyemo W.L., Ogunlewe M.O., Desalu I., et al.: Cleft deformities in adults and children aged over six years in Nigeria: Reasons for late presentation and management challenges. Clin. Cosmet Investig Dent. Nov., 30 (1): 6369, 2009.

24- Pelchat D., Bisson J., Richard N., et al.: Longitudinal effects of an early family intervention programme on the adaption of parents of children with disability. Int. J. Nurs. Stud., 36: 465-477, 1999.

25- Boo-Chai K.: The unoperated adult bilateral cleft of the lip and palate. Br. J. Plast. Surg. Jul., 24 (3): 250-257, 1971.

26- Greer Walker D.: Clefts of the palate and timing of the operation. In Transactions of the International Society of Plastic Surgeons, $2^{\text {nd }}$ Congr., I959, P.40 - Edinburgh: Livingstone, 1960.

27- Aziz S.R., Rhee S.T. and Redai I.: Cleft surgery in rural Bangladesh: Reflections and experiences. J. Oral Maxillofac. Surg., 67: 1581-1588, 2009.

28- Eipe N., Choudhrie A., Pillai A.D. and Choudhrie R.: Regional anesthesia for cleft lip repair: A preliminary study. Cleft Palate Craniofac. J. Mar., 43 (2): 138-141, 2006.

29- Fuller J., Drake D., Felstead A., et al.: Cleft Repair in Adults: A Report on a Case Series. Cleft Palate Craniofac. J. Aug., 55 (7): 1030-1034, 2018.

30- Fuller J., Felstead A., Brennan P., et al.: Technical challenges of adult cleft repair. Br. J. Oral Maxillofac. Surg., 54 (10): e171, 2016.

31- Alasseri N.A., Al Dhalaan N.A. and Almoraisi E.: Unusual presentation of unrepaired cleft lip in a fifty years old Saudi lady. Oral Maxillofac. Surg. Cases, 6 (4): 100204. https://doi.org/10.1016/j.omsc.2020.100204, 2020. 